\title{
Reinforcing Brain Stimulation and Memory in Monkeys
}

\author{
Eduardo Briese ${ }^{1}$ and James Olds \\ Department of Psychology, The University of Michigan, Ann Arbor, Michigan
}

Received June 8, 1964

\begin{abstract}
Sixty electrodes were implanted in various structures in the brain of two cynomologous monkeys subsequently trained to perform a three-position delayed response task. Each brain point was tested for the effects of electric stimulation, applied during the retention interval, on delayed response performance and for appetitive and aversive effects. At all points where there was clear evidence of approach or avoidance with respect to the brain stimulus, there was definite impairment of delayed response performance. In six of the twenty cases where there was possible evidence of approach or avoidance, there was impairment of delayed response. In none of the twenty-six cases where there was no evidence of approach or avoidance was there any evidence of impairment. The data were interpreted as indicating that the impairment produced by brain shocks could be accounted for by their appetitive or aversive effects.
\end{abstract}

\section{Introduction}

Previous work from this laboratory (15) indicated that noncontingent recurrent stimulation at "self-stimulation points" in rat brain caused disruption of a discrimination reversal problem. Similar stimulation at "aversive points" was ineffective. It was suggested that the electric brain stimulus rewarded the animal for making wrong responses, thereby preventing elimination of errors.

In the delayed response task, the electric brain stimulus can be confined to the delay or to the baiting intervals, i.c., to intervals which precede the response, thereby preventing its association, as a reward stimulus, with either right or wrong responses. Cianci (4) showed that stimulation of brain areas generally considered to represent "emotional substrates" disrupted the delayed response performance whether stimulation was applied during baiting or delay intervals. This suggested

1 Dr. Briese was on sabbatical leave from the Department of Physiology, Universidad de Los Andes, Merida, Venezuela. 
that there might be a close tie between the emotional effects of a stimulus and its capacity to impair delayed response performance even in a situation where no responses were rewarded or punished by the stimulus in question. To test this hypothesis, the positive and negative reinforcing effects of stimulation at various brain points were compared with effects of these same stimulations on delayed response performance.

\section{Methods}

The subjects were seven young male cynomologous monkeys. Five were used in preliminary tests to assess various methods and determine optimum procedures. Two were used in the final experiment. The first two animals used in preliminary tests had twenty and thirty implanted probes, respectively. There were thirty-nine probes in each of the remaining animals. Probes were used in brain stimulation tests only if resistance to the 60-cycle sine-wave stimulus fell between 20 and 30 kohms. Because nonconforming probes were eliminated, there were sixty brain points tested in the final experiments, twenty-six in one animal and thirty-four in the other. While data from all seven monkeys were similar in main respects, the modifications in method from case to case would make it confusing to report the data from all of them.

The surgery was carried out under pentobarbital anesthesia and semiaseptic conditions, but large doses of penicillin were administered during the first 2 weeks after surgery before any training was started. All probes were held in the same plastic block that was screwed and cemented to the skull (Fig. 1).

A three-choice delayed response test was used to make each trial maximally informative while permitting a high level of correct responding. One twenty-trial block differentiated clearly between the control level (one or two errors) and the chance level (thirteen or fourteen errors). A 6-sec delay was chosen because almost all animals showed relatively perfect three-choice performance with this brief delay even under conditions of distraction. With longer delays, stimulus conditions during tests made considerably more difference.

A 22- to 23-hour deprivation schedule was observed with watcr present at all times (during rest and test periods). Pellets $10 \times 10 \times 3$ $\mathrm{mm}$ were cut from standard monkey chow; these served to motivate several hundred trials in a hungry monkey. There were 100 trials daily, divided into five blocks of twenty trials for purposes of analysis and for 
imposition of the brain stimulation but not divided by any special pause between blocks. Each block of trials took about $10 \mathrm{~min}$. Animals were overtrained, being given 8,000 trials over a period of 4 months. They met a criterion of fifteen consecutive blocks with no more than three errors in any block.

The delayed response apparatus consisted of a board $25 \times 35 \mathrm{~cm}$ fastened in front of the primate chair in which an animal was placed (Fig. 2). Three oval cavities, $6 \mathrm{~mm}$ deep and $2.5 \times 2 \mathrm{~cm}$, were made in the

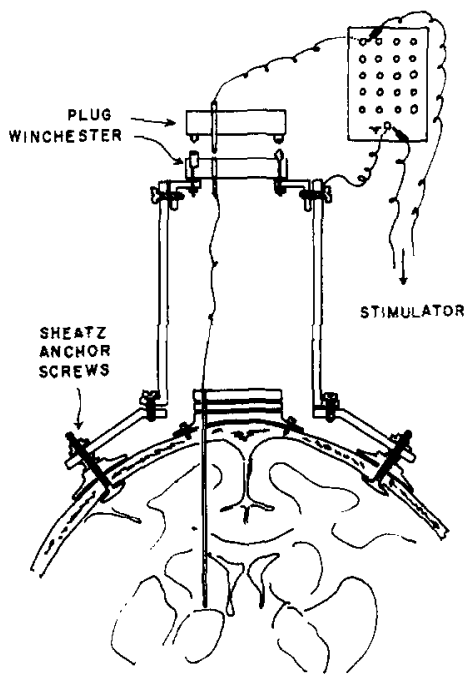

FIG. 1.

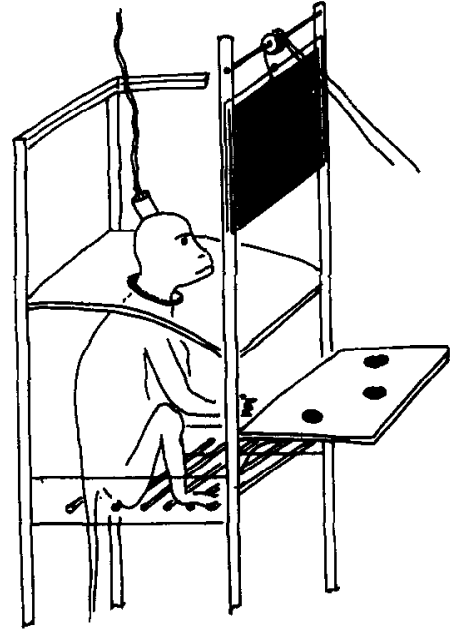

Fig. 2.

FIG. 1. Schematic drawing of electrode assembly and protective fence. For the sake of clarity only one electrode is shown.

FIG. 2. Schematic drawing of the primate chair used for delayed-response testing.

board to receive small bits of food. The centers of these depressions were $8 \mathrm{~cm}$ apart and were arranged in a semicircle. Each cavity had a a rotating lid which swung eccentrically on a pivot so that food could be placed in the cavity in full view of the monkey, after which all cavities were covered. Between the animal and the food board two screens (one transparent, the other opaque) could be raised and lowered by pulleys and strings. The raised opaque screen permitted the animal to see where the experimenter placed the bait while the plexiglass screen prevented it from reaching the food.

Dropping the opaque screen marked the start of the delay interval, 
during which all food receptacles were covered with their lids. At the end of the delay interval, both screens were raised and the monkey had free access to the board; the monkey was permitted to remove one of the lids and, if correct, take the food. Lowering of the double screen prevented the animal from trying more than one location. The same experimenter trained and tested both monkeys in the same section of a quiet room.

Escape and approach tests involved two manipulable levers; these took advantage of behaviors high in the animals' repertory of random responses. The levers were built into a table which could be substituted for the food board of the delayed response test. One lever was a metal square $10 \times 10 \mathrm{~cm}$ set flush with the table top; the other lever was a vertical wooden stick $1.5 \mathrm{~cm}$ in diameter and $10 \mathrm{~cm}$ long. Almost any contact with either lever tripped an underlying microswitch. The metal lever was used for self-stimulation (i.e., approach) tests, the wooden one for escape tests.

In self-stimulation tests, each lever response caused one train of stimulation to be applied via a selected electrode. During a 3-min period just prior to a given self-stimulation test, the experimenter repeatedly brought the animal into contact with the self-stimulation lever by various tricks and artifices so that the animal received at least thirty stimulations via a given electrode immediately before its use in a self-stimulation test; these stimulations were correlated as consequences to accidental, forced, or voluntary lever responses.

In escape tests, stimulation was in a series of brief trains which were applied at a rate of 1 per sec. Each response of the animal caused the series to be interrupted or postponed for a period of $4 \mathrm{sec}$; if one or more responses were made during the interruption, stimulation did not begin again until $4 \mathrm{sec}$ after the last lever response. In these tests, as in self-stimulation, the animal was brought into contact with the lever at least thirty times during the 3 min preceding a test.

A series of preliminary tests assessed electrodes one after another according to their arbitary enumeration, first for $3 \mathrm{~min}$ of escape and, immediately after, for $18 \mathrm{~min}$ of approach. To avoid negative reinforcement of manipulation of the positive lever, it was decided not to try to impose, in the first series, an approach test in relation to an electrode yielding a highly aversive effect in the first 3-min escape test. During all the following series of escape and approach tests, each point was 
assessed first for $6 \mathrm{~min}$ escape and next for 6 min approach. When a point showed strong escape or approach behavior, time was allowed for behavioral extinction to occur before testing the next point. The response outputs for these two 6-min periods defined the escape score and approach score, respectively. The sum of these two was the combined reinforcement score (Tables $1 \& 2$ ).

On the basis of the preliminary experiments, a current level of 150 $\mu$ amp (rms) was selected because it yielded self-stimulation in about one of three subcortical electrodes. It yielded escape in about one of six and disruption of delayed response in about one of three. The electric stimulus was a sine wave of $60 \mathrm{cycle} / \mathrm{sec}$ presented in trains of 0.5 -sec duration; current was monitored by means of a cathode-ray oscilloscope which measured the voltage across a constant resistor in series with the preparation.

In delayed response stimulation (DR-S) tests, electric stimuli were applied during DR-S blocks which were identical to control blocks except for the application of the electric stimulus. The stimuli were presented in five trains of $0.5 \mathrm{sec}$ each at a rate of 1 per sec for $5 \mathrm{sec}$ during the delay period; the series commenced $0.75 \mathrm{sec}$ after the opaque screen was dropped and ended $0.75 \mathrm{sec}$ before both screens were raised. In the escape test, the stimulus was applied in trains of $0.5 \mathrm{sec}$ at a rate of 1 per sec. Each response of the animal interrupted or postponed this series for 4 secs. In self-stimulation tests each lever response caused a single $0.5-\mathrm{sec}$ train of electric stimulation; responses during the train were ineffective.

Repeated DR-S tests were made because in preliminary experiments, stimulation with electrodes at some brain points was disruptive at first but the effects declined on repetition. In order to rule out such temporary effects, six series of DR-S tests were made in each monkey; each series consisted of one block for each electrode. The average error score for the last four of these six blocks was used to characterize the disrupting effects from stimulating a given electrode point.

There was an interdigitation of DR-S tests with escape and approach (E-A) tests. After preliminary DR training, there were, in both monkeys, two preliminary E-A series, two preliminary DR-S series, the final E-A series, and the four final DR-S series. In both cases, the final E-A series was followed immediately by the four final DR-S series; only scores for these final series were used. 
TABLE 1

Analysis of the Electrodes IN Monkey No. 6

\begin{tabular}{|c|c|c|c|c|}
\hline Locus & $\begin{array}{l}\text { Mean } \\
\text { errors }\end{array}$ & $\begin{array}{c}\text { Escape } \\
\text { score } \\
(6 \mathrm{~min})\end{array}$ & $\begin{array}{c}\text { Approach } \\
\text { score } \\
(6 \mathrm{~min}) \\
\end{array}$ & $\begin{array}{l}\text { Combined } \\
\text { Rein- } \\
\text { forcement } \\
\text { score }\end{array}$ \\
\hline Colliculus inferior & 13.5 & 357 & 0 & 357 \\
\hline Decussatio brachii conjunctivi & 11.2 & 42 & 363 & 405 \\
\hline Chiasma opticum & 11.0 & 377 & 5 & 382 \\
\hline Capsula interna ; caudatus (vent.) & 9.7 & 70 & 451 & 521 \\
\hline Nu. lemnisci diagonalis & 8.2 & 172 & 130 & 302 \\
\hline Nu. medialis dorsalis thalami & 8.2 & 44 & 84 & 128 \\
\hline Substantia nigra (ventromed.) & 7.2 & 1 & 333 & 334 \\
\hline \multicolumn{5}{|l|}{ Capsula interna; area } \\
\hline hypothalamica lateralis & 6.7 & 97 & 247 & 344 \\
\hline Zona incerta; Forel $\mathrm{H}_{1}$ & 5.5 & 129 & 196 & 325 \\
\hline \multicolumn{5}{|l|}{ Capsula interna ; area } \\
\hline hypothalamic lateralis & 5.5 & 137 & 224 & 361 \\
\hline Substantial nigra (dorsolat.) & 5.2 & 34 & 105 & 139 \\
\hline Stria terminalis & 4.7 & 180 & 194 & 374 \\
\hline Substantia nigra (dorsomed.) & 4.7 & 55 & 148 & 203 \\
\hline Nu. amygdalae basalis accessorius & 4.5 & 167 & 0 & 167 \\
\hline Area amydaliformis anterior & 4.2 & 92 & 316 & 408 \\
\hline Hippocampus (near nu. amygdalae basalis) & 3.5 & 44 & 0 & 44 \\
\hline Nu. caudatus (mid.) & 3.2 & 23 & 0 & 23 \\
\hline $\mathrm{Nu}$. interpeduncularis & 3.0 & 30 & 77 & 107 \\
\hline \multicolumn{5}{|l|}{ Nu. ventralis } \\
\hline posterolateralis thalami & 3.0 & 27 & 0 & 27 \\
\hline $\mathrm{Nu}$ reticularis parvocellularis & 2.5 & 32 & 0 & 32 \\
\hline Corpus geniculatum mediale & 2.2 & 43 & 51 & 94 \\
\hline Commissura anterior; globus pallidus & 2.2 & 14 & 0 & 14 \\
\hline Nu. pulvinaris lateralis thalami & 2.2 & 30 & 50 & 80 \\
\hline Putamen & 2.0 & 92 & 75 & 167 \\
\hline Ventriculus lateralis & 2.0 & 44 & 5 & 49 \\
\hline \multicolumn{5}{|l|}{ Nu. ventralis } \\
\hline posteromedialis thalami & 2.0 & 2 & 0 & 2 \\
\hline $\mathrm{Nu}$. caudatus (mid.) & 1.7 & 33 & 0 & 33 \\
\hline Area pretectalis & 1.7 & 37 & 107 & 144 \\
\hline Out of brain & 1.7 & 101 & 10 & 111 \\
\hline \multicolumn{5}{|l|}{ Nu. caudatus (vent.) } \\
\hline near capsula interna & 1.7 & 104 & 42 & 146 \\
\hline \multicolumn{5}{|l|}{ Nu. ventralis } \\
\hline posterolateralis thalami & 1.5 & 50 & 49 & 99 \\
\hline Nu. caudatus (mid.) & 1.2 & 62 & 0 & 62 \\
\hline Substantia nigra & 1.0 & 10 & 174 & 184 \\
\hline \multicolumn{5}{|l|}{$\mathrm{Nu}$. ventralis } \\
\hline posteromedialis thalami & 0.2 & 77 & 14 & 91 \\
\hline
\end{tabular}




\section{Results}

At points yielding either self-stimulation or escape, stimulation was far more apt to cause high error scores on the delayed response test than stimulation at points which had no marked reinforcing effects. Of the nineteen points having mean error scores of 4 to 14 , fourteen had combined reinforcement scores above 200; of the other forty-one points with mean error scores of less than 4 , not one had a combined reinforcement score of such magnitude (Tables $1 \& 2$ and Fig. 3 ).

In both animals the correlation of error scores with reinforcing scores

TABLE 2

ANalysis of the Electrodes In Monkey No. 7

\begin{tabular}{|c|c|c|c|c|}
\hline Locus & $\begin{array}{l}\text { Mean } \\
\text { errors }\end{array}$ & $\begin{array}{c}\text { Escape } \\
\text { score } \\
(6 \mathrm{~min})\end{array}$ & $\begin{array}{l}\text { Approach } \\
\text { score } \\
(6 \mathrm{~min})\end{array}$ & $\begin{array}{l}\text { Combined } \\
\text { rein- } \\
\text { forcement } \\
\text { score }\end{array}$ \\
\hline Substantia nigra (dor.) & 11.5 & 47 & 489 & 536 \\
\hline \multicolumn{5}{|l|}{ Nu. paracentralis or } \\
\hline nucleus medialis dorsalis thalami & 9.0 & 6 & 145 & 151 \\
\hline Nu. caudatus (med.) & 5.5 & 67 & 307 & 374 \\
\hline Area preoptica & 4.5 & 17 & 67 & 84 \\
\hline Nu. caudatus (med.) & 4.0 & 14 & 141 & 155 \\
\hline Capsula interna; pes pedunculi & 3.7 & 7 & 61 & 68 \\
\hline Substantia nigra (lat.) & 3.5 & 14 & 23 & 37 \\
\hline Area preoptica; commissura anterior & 3.2 & 1 & 0 & 1 \\
\hline Area hypothalamica lateralis & 3.2 & 26 & 115 & 141 \\
\hline Commissura anterior (dor.) & 3.2 & 2 & 103 & 105 \\
\hline Nu. pulvinaris thalami & 3.0 & 0 & 3 & 3 \\
\hline Ventralis lateralis & 2.7 & 6 & 33 & 39 \\
\hline Nu. panafascicularis thalami & 2.5 & 0 & 0 & 0 \\
\hline Capsula interna & 2.5 & 5 & 0 & 5 \\
\hline Nu. caudatus (mid.) & 2.2 & 18 & 7 & 25 \\
\hline \multicolumn{5}{|l|}{ Forel $\mathrm{H}_{1}$; nu. ventralis } \\
\hline lateralis thalami & 2.0 & 7 & 0 & 7 \\
\hline Nu. ventralis posteromedialis thalami & 2.0 & 1 & 24 & 25 \\
\hline Putamen & 1.7 & 7 & 0 & 7 \\
\hline Corpus callosum & 1.7 & 20 & 7 & 27 \\
\hline Corpus callosum & 1.5 & 10 & 8 & 18 \\
\hline Corpus callosum & 1.5 & 0 & 0 & 0 \\
\hline Nu. caudatus (dor.) & 1.5 & 3 & 1 & 4 \\
\hline Putamen (vent.) & 1.2 & 0 & 7 & 7 \\
\hline Stratum superficiale pontis & 1.2 & 3 & 0 & 3 \\
\hline Nu. interstitialis posterior & 1.0 & 0 & 0 & 0 \\
\hline \multicolumn{5}{|l|}{ Nu. ventralis } \\
\hline posterolateralis thalami & 0.7 & 4 & 0 & 4 \\
\hline
\end{tabular}




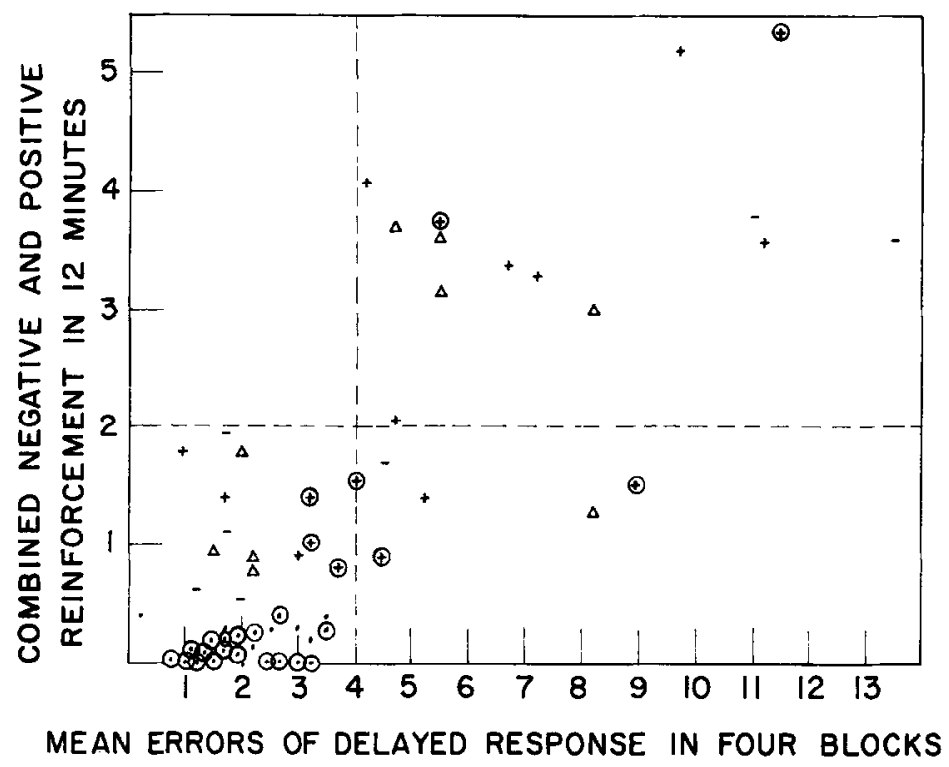

FIG. 3. Correlation matrix relating error and reinforcement scores; the numbers along the ordinate represent hundreds of responses. Symbols represent sixty brain points where stimulation had effects as follows: $+=$ mainly positive reinforcement; $-=$ mainly negative reinforcement; $\Delta=$ positive and negative reinforcement from the same electrode; $\bullet=$ neutral; circled symbols are from monkey No. 7. Points were labeled $\Delta$ if the lower of the two reinforcement scores was more than $50 \%$ of the higher onc.

was significant (Table 3). Correlation with escape scores was higher in one animal and correlation with self-stimulation scores was higher in the other. Correlation coefficients between error scores and combined reinforcement scores of +0.7 to +0.8 indicated that stimulation of brain-

TABLE 3

Product Moment Correlation Coefficients of Error Scores AND ReInforcing Scores

\begin{tabular}{lcc}
\hline & \multicolumn{2}{c}{ Correlation coefficient } \\
\cline { 2 - 3 } & Animal No.6 & Animal No. 7 \\
Self-stimulation & $+0.458^{a}$ & $+0.856^{b}$ \\
Escape & $+0.602^{b}$ & $+0.572^{a}$ \\
Self-stimulation + escape & $+0.730^{b}$ & $+0.849^{b}$ \\
\hline
\end{tabular}

$a$ Such a correlation would occur only by chance less than one time in 100 .

${ }^{b}$ Such a correlation would occur only by chance less than one time in 1000 . 


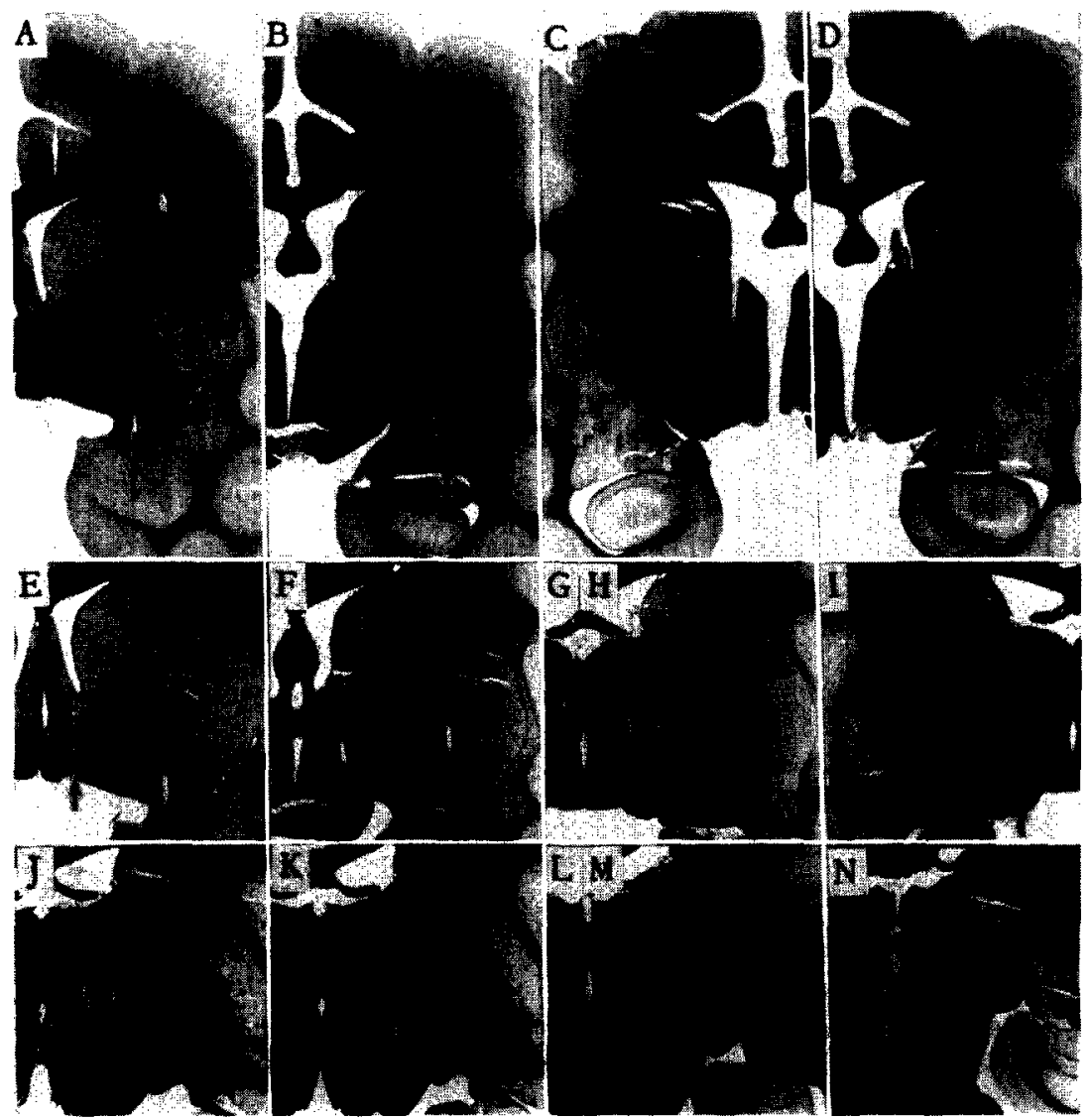

FIG. 4. Brain sections of animal No. 6 showing deepest part of electrode tracks. It is assumed that the region within 1-2 mm of the ventralmost part of the track was within the suprathreshold electrical field during stimulation. Most of the points shown yielded high self-stimulation (ss) scores and high error (er) scores. Points shown in $\mathrm{B}$ and $\mathrm{C}$ were close to points yielding high self-stimulation but they themselves yielded almost no self-stimulation; thus they suggest boundaries of the system. Brain areas stimulated and scores produced were as follows: (A) area amygdaliformis anterior, self-stimulation score - 316, escape score - 92, error score, 4.2 ; (B) nucleus amygdalae basalis accessorius, ss -0 , es -167 , er -4.5 ; (C) nucleus caudatus (vent.), ss -42 , cs -104 , er -1.7 ; (D) capsula interna, ss -451 , es -70 , er -9.7 ; (E) nucleus lemnisci diagonalis, ss -130 , es -172 , er - 8.2; (F) stria terminalis, ss - 194, es - 180, er - 4.7; ( $G$ and $H)$ capsula interna (left arrow) and area hypothalamica lateralis (right arrow), (G) ss -224 , es -137 , er -5.5 , (H) ss - 247, es - 97, er - 6.7; (I) substantia nigra, ss - 333, es -1 , er -7.2 ; ( J) zona incerta, ss -196 , es -129 , er -5.5 ; (K) substantia nigra, ss -105 , es -34 , er -5.2 ; ( $L$ and $M$ ) substantial nigra (both arrows), (L) ss -148 , es -55 , er -4.7 , (M) ss -174 , es -10 , er -1.0 ; (N) decussatio brachii conjunctivi, ss -363 , es -42 , er -11.2 . 
stem points which caused disruption of delayed response was mainly the same as that which caused either positive or negative reinforcement.

Anatomical Findings. Self-stimulation was produced in animal No. 6 with a probe in the anterior amygdaloid area; escape responses were produced by a nearby probe in the accessory basal nucleus of amygdala (Fig. 4A, B) (cf. 27). Probes in the subseptal area, which is pervaded by diagonal band and stria terminalis, also yielded mild self-stimulation

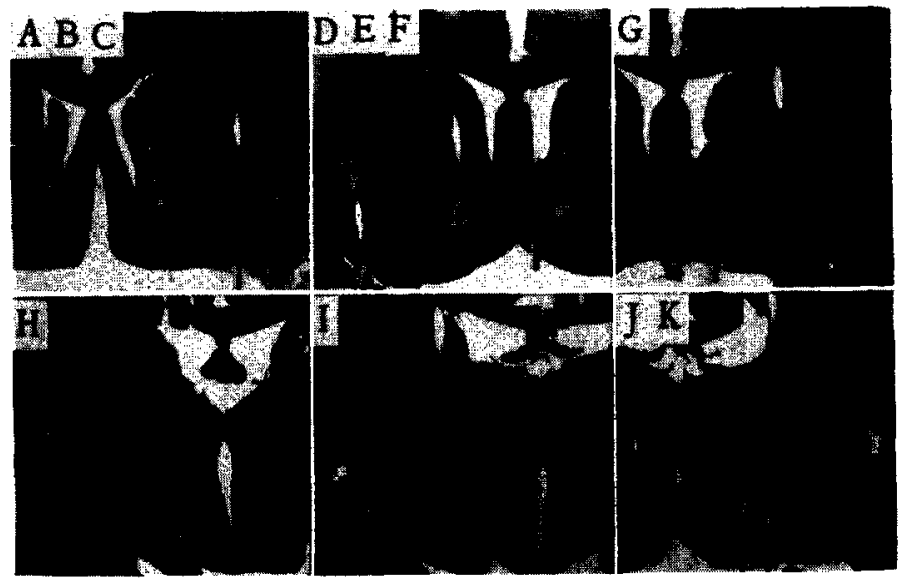

Frg. 5. Brain sections of animal No. 7 showing deepest part of electrode tracks. As in Fig. 4, sections were chosen to illustrate points yielding high self-stimulation and error scores. Brain areas stimulated and scores produced were as follows: (A, B and $C$ ) nucleus caudatus (left arrow), nucleus caudatus (middle arrow) and putamen (right arrow), (A) ss -307 , es -67 , er -5.5 , (B) ss -141 , es -14 , er -4 , (C) $\mathrm{ss}-7$, es -0 , er -1.2 ; (D, E and F) putamen (left arrow), commissura anterior (middle arrow) and area preoptica (right arrow), (D) ss -0 , es - 7, er 1.7 , (E) ss -103 , es -2 , er -3.2 , (F) ss -0 , es -1 , er -3.2 ; (G) area preoptica, ss -67 , es -17 , er $-4.5 ;(\mathrm{H})$ area hypothalamica lateralis, ss -115 , es -26 , er -3.2 ; (I) capsula interna, ss -61 , es -7 , er -3.7 ; ( $\mathrm{J}$ and $\mathrm{K}$ ) substantia nigra (both arrows), (J) ss -489 , es -47 , er -11.5 , (K) ss -23 , es -14 , er -3.5 .

(Fig. 4E, F). One probe in the ventral caudate just above the internal capsule failed to yield self-stimulation, while a similarly placed probe in the internal capsule produced very high self-stimulation rates (Fig. $4 C, D$ ). Self-stimulation was also caused with probes in the medial forebrain bundle regions of the hypothalamus, as was previously found in rat (16), cat (26), and monkey (1); these regions included the point at which the internal capsule passes through the lateral hypothalamic area and the regions below the zona incerta and above the substantia 
nigra (Fig. 4G-M). Self-stimulation was also produced posteriorly with probes at a point proximal to the decussation of the brachium conjunctivum (Fig. 4N).

In animal No. 7, self-stimulation was elicited with two probes in the medial caudate nucleus (Fig. 5A, B), with one in a dorsal part of the anterior commissure (Fig. $5 \mathrm{E}$ ) and with probes in the lateral hypothalamus and above the substantia nigra (Fig. $5 \mathrm{H}, \mathrm{J}$ ).

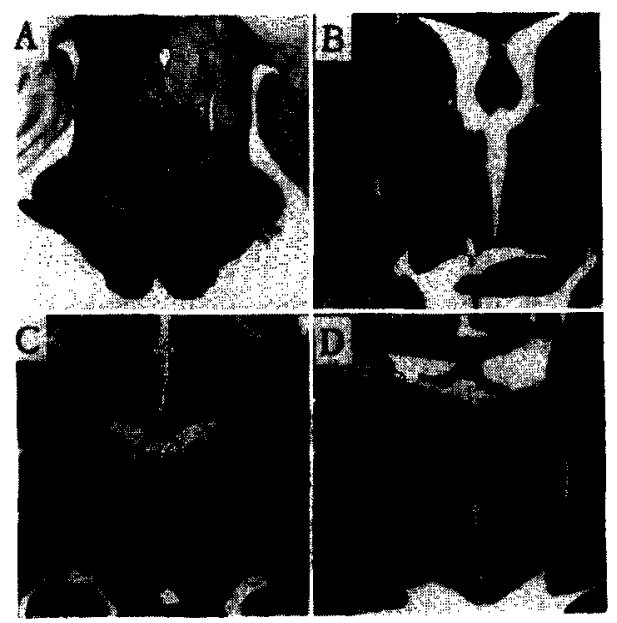

Fic. 6. A and B. Brain sections from animal No. 6 showing points of primary sensory system which yielded high escape and error scores. It was mainly these two primary system points that accounted for the high correlation between errors and escape scores. (A) inferior colliculus, ss -0 , es -357 , er -13.5 ; (B) chiasma nervorum opticorum, ss -5 , es -377 , er $-11.0 . \mathrm{C}$ and $\mathrm{D}$. Brain sections from animals No. 6 and No. 7, illustrating points in nucleus medialis dorsalis thalami which yielded very high error scores with low reinforcement scores. (C) nucleus medialis dorsalis thalami, ss -84 , es -44 , er -8.2 ; (D) nucleus medialis dorsalis thalami, ss -145 , es -6 , er -9.0 .

In animal No. 6, escape without self-stimulation was elicited with probes in basal amygdala (Fig. 4B), optic chiasma, and inferior colliculus (Fig. 6A, B).

Also in animal No. 6, ambivalent responses, i.e., similar rates of selfstimulation and escape, were produced with probes in diagonal band (Fig. 4E), stria terminalis (Fig. 4F), the internal capsule part of the lateral hypothalamus (Fig. $4 \mathrm{G}, \mathrm{H}$ ), and part of the zona incerta (Fig. $4 \mathrm{~J})$.

There were two points, one in each animal, in or near nucleus medialis 
dorsalis of the thalamus which yielded very high error scores, scores that were disproportionately high when compared with the reinforcement scores (Fig. 6C, D). In both cases, however, there was some small tendency to self-stimulation.

\section{Discussion}

Although brain stimuli were applied during the memory (retention) interval, aftereffects may have been present during the other intervals. Electric brain stimuli probably have appreciable aftereffects resulting partly from afterdischarges, partly from psychological consequences. Weiskrantz, Mihailovic and Gross (25) stimulated $1 \mathrm{sec}$ out of every $4 \mathrm{sec}$, irrespective of when the stimulus occurred in the course of a trial and thereby were able to drive delayed alternation performance almost to chance levels with stimulation in the principal sulcus of the frontal lobe. Aftereffects filled 3 of every $4 \mathrm{sec}$. That the aftereffects during the 3 -sec interstimulus intervals might have been more significant than the effects during the stimulus intervals was suggested by comparison with the earlier work of Stamm and Pribram (22) and Stamm (21). These earlier studies seemed to indicate that continuous stimulation with electrodes in frontal cortical positions during delayed response testing could be carried to the point of producing seizures without upsetting delayed alternation in the overtrained animal. One possible interpretation of the difference between these results and those of Weiskrantz, Mihailovic and Gross was that rebound aftereffects during the 3-sec interstimulus intervals of the Weiskrantz group were more disruptive than effects during stimulation itself.

Cianci (4) observed important aftereffects when stimulation was applied to certain structures, including the commissure of the superior colliculus, the hypothalamus, the anterior thalamic nuclei, the anterior commissure, the diagonal band, and the sulcus frontalis. In these cases a series of ten delayed-response trials which followed cessation of a series of stimulated trials suffered significantly by comparison with other control scores.

Thus application of the disrupting stimulus during the memory interval did not necesarily limit the effects of the disrupting stimulus to the memory interval; some effects may have been carried over into other intervals and therefore affected other functions.

Because most of the points producing disruption of performance also produced marked reinforcing results, the possibility that the primary 
disturbance was emotional or motivational should be seriously considered. If this were the case, then the disruption of delayed response might have resulted from either disruption of a mnemonic process by extreme emotion (e.g., the animal might have been so frightened that he forgot) or a motivational change which obscured an intact mnemonic mechanism (e.g., intracranial stimulation might have been so rewarding as to render food uninteresting) (5). Possibly arguing against such an interpretation is Ławicka's (9) evidence that an additional alimentary reward inserted during the delay interval did not interfere with the performance of the delayed response in dogs and cats.

We are still left with two questions. First, are there any anatomical locations in which electric stimulation may disrupt the memory trace without also having a motivational effect? And second, if there are none or very few, why?

In answer to the first question, the work of Weiskrantz, Mihailovic and Gross (25) and Rosvold and Delgado (20) seemed to indicate points in the frontal lobe and caudate, respectively, yielding mnemonic effects. The effective points in the study of Rosvold group appeared to us to have been in portions of the caudate which might be expected to produce positive reinforcement on the electric stimulation, but the effective points of Weiskrantz's group appeared to be in the neocortex where stimulation would not be expected to yield reinforcing effects $(6,10,13)$. However, in this case it was possible to assume that rebound from stimulation was more disruptive than stimulation itself. If so, the effect would be similar to extirpation of frontal lobes, which impairs delayed response performance possibly by releasing lower motive centers from frontal lobe inhibition (2), an effect which, according to one report (24), might be counteracted by pentobarbital. Even in this instance, a diffuse emotional effect would have to be considered.

In the present study, there were two points, one in each animal, which produced very large mnemonic deficits in conjunction with relatively low motive scores. In both cases, electrodes were in or near the nucleus medialis dorsalis of the thalamus (Fig. 6C, D). Cianci's study (4) showed a similar deficit produced by stimulating the same area. But in cat, stimulation in the nucleus medialis dorsalis has been reported to yield aversive effects (19). It is unclear why negative reinforcement in the present cases did not result from stimulation in this area. In fact, both monkeys showed some moderate positive reinforcement from stimulation in the medialis dorsalis; in neither case was there indication of 
definite negative reinforcement. However, our own data and that of Roberts (19) made it clear that a relation of the nucleus medialis dorsalis to emotional processes could not be ruled out.

The nucleus medialis dorsalis is closely connected with the frontal lobes, the removal of which has regularly been correlated with deficit in delayed response (cf. 23). Nevertheless, lesions in nucleus medialis dorsalis have not had the same effect (3). If we now consider that continuous stimulation of frontal lobes may not produce deficit but that such deficit is produced by ablation and possibly by rebound effects, and that lesions in nucleus medialis dorsalis do not produce deficit but stimulation there does, we are confronted with possible reciprocal relations between the cortical and thalamic poles of this system.

Why has there so far been a failure to discover a large system of easily defined points yielding clearcut disruption of mnemonic process without concomitant motivational effects? It may simply be that we have not yet probed in the right places to find such mnemonic centers, if they exist. Or it may be that traces are located in a wide variety of equipotential systems (8), and therefore cannot be disrupted except by diffuse stimulation. If diffuse or nonspecific brain systems were required, and if these were regularly involved in motivational processes, which seems likely (14), this would explain the correlation of motivational and mnemonic effects of brain stimulation. An alternative would be that mnemonic and motivational systems run a closely parallel or even an interdigitated course. A similar suggestion seemed implied by Penfield and Jasper (17) and Milner (12) who analyzed human clinical material to indicate effects on memory by stimulating and ablating hippocampal and temporal lobe points, points classically associated with the so-called olfactory or visceral brain $(7,11,18)$.

\section{References}

1. BRADY, J. V. 1961. Motivational-emotional factors and intracranial self-stimulation, pp. 413-430. In "Houston Symposium on Brain Stimulation, Subcortical Integrative Systems," D. Scheer [ed.]. Univ. of Texas Press, Austin, Texas.

2. BRUTKowski, S. 1959. Comparison of classical and instrumental alimentary conditioned reflexes following bilateral prefrontal lobotomy in dogs. Acta Biol. Exptl. Polish Acad. Sci. 19: 291-299.

3. Chоw, K. L. 1954. Lack of behavioral effects following destruction of some thalamic association nuclei. A. M. A. Arch. Neurol. Psychiat. 71: 762-771.

4. Cianci, S. N. 192. The effects of intracranial electric stimulation on the 
delayed-response test in monkeys. Dissertation, Univ. of Michigan, Ann Arbor, Michigan.

5. Crespr, L. P. 1942. Quantitative variation of incentive and performance in white rat. Am. J. Psychol. 65: 467-517.

6. Delgado, J. M. R., W. W. Roberts, and N. E. Miller. 1954. Learning motivated by electrical stimulation of the brain. Am. J Physiol. 179: 587-593.

7. KLÜver, H., and P. C. BUCY. 1939. Preliminary analysis of functions of the temporal lobes in monkeys. A. M. A. Arch. Neurol. Psychiat. 42: 979-1000.

8. Lashley, K. S. 1929. "Brain mechanisms and intelligence: a quantitative study of injuries to the brain." Univ. of Chicago Press, Chicago, Illinois.

9. LAWICKA, W. 1959. The physiological mechanism of delayed reactions. II. Delayed reactions in dogs and cats to directional stimuli. Acta Biol. Exptl. Polish Acad. Sci. 19: 199-220.

10. Lilly, J. C. 1959. Discussion: (Brain Stimulation and Conditioned Reflexes, by R. W. Doty), pp. 247-303. In "The Central Nervous System and Behavior," Vol. 1 Trans. First Conference, Josiah Macy, Jr. Foundation, Princeton, N. J., Feb. 23-26, 1958, M. A. B. Brazier [ed.]. Madison Printing Co., Madison, New Jersey.

11. Maclean, P. D. 1949. Psychosomatic disease and the "visceral brain." Psychosomat. Med. 11: 338-353.

12. Milner, B. 1958. Psychological defects produced by temporal lobe excision. Res. Publ. Ass. Res. Nervous Mental Disease. 36: 244-257.

13. OLDs, J. 195. A preliminary mapping of electrical reinforcing effects in the rat brain. J. Comp. Physiol. Psychol. 49: 281-285

14. Olds, J., and B. Peretz. 1960. A motivational analysis of the reticular activating system. Electroencephalog. Clin. Neurophysiol. 12: 445-454.

15. OLDs, M. E., and J. Ouds. 1961. Emotional and associative mechanisms in rat brain. J Comp. Physiol. Psychol. 54: 120-126.

16. Olds, M. E., and J. Olds. 1963. Approach-avoidance analysis of rat diencephalon. J. Comp. Neurol. 102: 259-295.

17. Penfield, W., and H. JAsper. 1954. "Epilepsy and the functional anatomy of the human brain." Little, Bown \& Co., Boston, Massachusetts.

18. Prtbram, K. H., and L. Kruger. 1954. Functions of the "olfactory brain." Ann. N. Y. Acad. Sci. 58: 109-138

19. Roberts, W. W. 1962. Fear-like behavior elicited from dorsomedial thalamus of cat. J. Comp. Physiol. Psychol. 55: 191-198.

20. Rosvold, H. E., and J. M. R. Delgado. 1956. The effect on delayed alternation test performance of stimulating or destroying electrically structures within the frontal lobes of the monkey's brain. J. Comp. Physio. Psychol. 49: $365-372$.

21 Stamm, J. S. 1961. Electrical stimulation of frontal cortex in monkeys during learning of an alternation task. J. Neurophysiol. 24: 414-426.

22. Stamm, J. S., and K. H. Pribram. 1960. Effects of epileptogenic lesions in frontal cortex on learning and retention in monkeys. J. Neurophysiol. 23: 552-563.

23. Stanley, W. C., and J. Jaynes. 1949. The functions of the frontal cortex. Psychol. Rev. 56: 18-32. 
24. WADE, M. 1947. The effect of sedatives upon delayed responses in monkeys following removal of the prefrontal lobes. J. Neurophysiol. 10: 57-61.

25. Weiskrantz, L., L. J. Mihailovic, and C. G. Gross. 1962. Effects of stimulation of frontal cortex and hippocampus on behavior in the monkey. Brain 85: $487-504$.

26. Wilkinson, H., and T. L. Peele. 1963. Intracranial self-stimulation in cats. J. Comp. Physiol. Psychol. 121: 425-440.

27. Wurtz, R. H, and J. OLds, 1963. Amygdaloid stimulation and operant reinforcement. J. Comp. Physiol. Psychol. 56: 941-949. 